\title{
Cloud Influence on ERA5 and AMPS Surface Downwelling Longwave Radiation Biases in West Antarctica ${ }^{\mathscr{O}}$
}

\author{
ISRAEl Silber, ${ }^{\mathrm{a}}$ JOHANNES VERLinde, ${ }^{\mathrm{a}}$ SHENG-Hung WANG,${ }^{\mathrm{b}}$ DAVID H. BrOMWich,,${ }^{\mathrm{b}, \mathrm{c}}$ \\ AnN M. Fridlind, ${ }^{\mathrm{d}}$ MARia CADEddu, ${ }^{\mathrm{e}}$ Edwin W. Eloranta, ${ }^{\mathrm{f}}$ AND CONNOR J. Flynn ${ }^{\mathrm{g}}$ \\ ${ }^{a}$ Department of Meteorology and Atmospheric Science, The Pennsylvania State University, University Park, Pennsylvania \\ ${ }^{\mathrm{b}}$ Polar Meteorology Group, Byrd Polar and Climate Research Center, The Ohio State University, Columbus, Ohio \\ ${ }^{c}$ Atmospheric Sciences Program, Department of Geography, The Ohio State University, Columbus, Ohio \\ ${ }^{\mathrm{d}}$ NASA Goddard Institute for Space Studies, New York, New York \\ e Argonne National Laboratory, Argonne, Illinois \\ ${ }^{\mathrm{f}}$ Space Science and Engineering Center, University of Wisconsin-Madison, Madison, Wisconsin \\ ${ }^{g}$ Pacific Northwest National Laboratory, Richland, Washington
}

(Manuscript received 1 March 2019, in final form 1 August 2019)

\begin{abstract}
The surface downwelling longwave radiation component (LW $\downarrow$ ) is crucial for the determination of the surface energy budget and has significant implications for the resilience of ice surfaces in the polar regions. Accurate model evaluation of this radiation component requires knowledge about the phase, vertical distribution, and associated temperature of water in the atmosphere, all of which control the LW $\downarrow$ signal measured at the surface. In this study, we examine the LW $\downarrow$ model errors found in the Antarctic Mesoscale Prediction System (AMPS) operational forecast model and the ERA5 model relative to observations from the ARM West Antarctic Radiation Experiment (AWARE) campaign at McMurdo Station and the West Antarctic Ice Sheet (WAIS) Divide. The errors are calculated separately for observed clear-sky conditions, ice-cloud occurrences, and liquid-bearing cloud-layer (LBCL) occurrences. The analysis results show a tendency in both models at each site to underestimate the $\mathrm{LW} \downarrow$ during clear-sky conditions, high error variability (standard deviations $>20 \mathrm{~W} \mathrm{~m}^{-2}$ ) during any type of cloud occurrence, and negative LW $\downarrow$ biases when LBCLs are observed (bias magnitudes $>15 \mathrm{~W} \mathrm{~m}^{-2}$ in tenuous LBCL cases and $>43 \mathrm{~W} \mathrm{~m}^{-2}$ in optically thick/ opaque LBCLs instances). We suggest that a generally dry and liquid-deficient atmosphere responsible for the identified LW $\downarrow$ biases in both models is the result of excessive ice formation and growth, which could stem from the model initial and lateral boundary conditions, microphysics scheme, aerosol representation, and/or limited vertical resolution.
\end{abstract}

\section{Introduction}

The surface energy budget in the polar regions is controlled by the amount, phase, and distribution of water in the atmosphere. Water is often advected from open-water sources, located mainly at lower latitudes, into the polar regions by meso- and synoptic-scale systems (Carrasco et al. 2003; Nigro and Cassano 2014; Pithan et al. 2018). Some of these moist and warm air intrusions accompanied by cloud formation have been

Supplemental information related to this paper is available at the Journals Online website: https://doi.org/10.1175/10.1175/JCLID-19-0149.s1.

Corresponding author: Israel Silber, israel0silber@gmail.com shown to result in extensive ice sheet melting events (Bennartz et al. 2013; Nicolas et al. 2017), enhancement of meltwater runoff (Van Tricht et al. 2016), and sea ice decline (Francis and Hunter 2006).

The synoptic-scale patterns of moisture advection into the polar regions are generally well captured by models (e.g., Coggins and McDonald 2015; Nicolas and Bromwich 2011; Scott et al. 2019; Scott and Lubin 2014; Sedlar and Tjernström 2017; Woods et al. 2013). However, discrepancies between observations and largescale model representation of polar-cloud properties and occurrence are often reported (e.g., Cesana et al. 2012; Klein et al. 2009). These modeled cloud deviations from the measurements likely result from incomplete understanding and difficulties in the model representation of mixed-phase cloud microphysical processes, such 
as ice-formation mechanisms and ice-crystal growth (e.g., van Diedenhoven et al. 2009; Fridlind and Ackerman 2018; Harrington et al. 2013). The outcome of such discrepancies is poorly modeled atmospheric profiles of water-phase partitioning that, together with an inaccurate prediction of hydrometeor properties, can generate biases in the model estimations of the surface energy budget. These surface radiation biases are largely dominated in the polar regions by the surface downwelling longwave ( $\mathrm{LW} \downarrow$ ) component, which is highly sensitive to the water distribution in the atmosphere and its properties (e.g., phase, temperature; see Bennartz et al. 2013; Ohmura 2001; Persson et al. 2017; Shupe and Intrieri 2004).

Large-scale model intercomparisons of the LW $\downarrow$ in Antarctica, performed at various temporal resolutions, from $3 \mathrm{~h}$ to full seasons, were reported by several studies. These intercomparisons were made with climate models (e.g., Lenaerts et al. 2017), regional climate and forecast models (e.g., Bromwich et al. 2013; Hines et al. 2019; King et al. 2015), and reanalysis models (e.g., Välisuo et al. 2014; Wang and Dickinson 2013), which were evaluated using satellite measurement data products (e.g., Lenaerts et al. 2017; van Wessem et al. 2018) and ground-based measurements (e.g., Välisuo et al. 2014; Valkonen et al. 2014; Wang and Dickinson 2013). These studies showed predominantly large mean model relative bias and standard deviation (SD) that occasionally exceeded 10 and $30 \mathrm{~W} \mathrm{~m}^{-2}$, respectively, and moderate Pearson's correlation coefficient $(r)$ values within the 0.5-0.8 range (Bromwich et al. 2013; King et al. 2015; Listowski and Lachlan-Cope 2017; Välisuo et al. 2014; van Wessem et al. 2018). The sources for these high model biases and moderate $r$ values were consistently attributed to the poor model prediction of cloud physical properties (e.g., Bromwich et al. 2013; King et al. 2015; Lenaerts et al. 2017), although these conclusions were made without separately quantifying the model biases for cloudy periods. For instance, Listowski and LachlanCope (2017) supported their conclusion by pointing to the reduction in the model bias and SD when more advanced cloud microphysical schemes were implemented in a regional forecast model.

In this study, we examine the LW $\downarrow$ bias of the Antarctic Mesoscale Prediction System (AMPS) regional forecast model (Powers et al. 2012) and the latest, fifth version of the European Centre for Medium-Range Weather Forecasts (ECMWF) reanalysis model ERA5 (Hersbach and Dee 2016). The biases are calculated relative to comprehensive surface observations gathered at McMurdo Station $\left(77.85^{\circ} \mathrm{S}, 166.72^{\circ} \mathrm{E} ; 70 \mathrm{~m}\right.$ above mean sea level) and the West Antarctic Ice Sheet (WAIS) Divide $\left(79.47^{\circ} \mathrm{S}, 112.08^{\circ} \mathrm{W} ; 1803 \mathrm{~m}\right.$ above mean sea level) during the U.S. Department of Energy (DOE) Atmospheric Radiation Measurement (ARM) West Antarctic Radiation Experiment (AWARE) field campaign (Lubin et al. 2015; Witze 2016). We isolate and compare the biases generated during the occurrence of tenuous and opaque liquid-bearing clouds, ice clouds, and clear-sky periods. Finally, we discuss the results and potential bias sources.

\section{Methodology}

\section{a. Observational data}

We follow the methodology of Silber et al. (2018a) and Silber et al. (2019) for the detection of clouds and phase classification at McMurdo Station and the WAIS Divide, respectively. These methods are based mainly on the analysis of the Ka-band ARM zenith radar (KAZR; Widener et al. 2012) and the high-spectralresolution lidar (HSRL; Eloranta 2005) measurements at McMurdo, and the polarization-sensitive micropulse lidar (MPL; Flynn et al. 2007) at the WAIS Divide, the raw measurements of which were processed by the authors (Silber et al. 2018b). The Vaisala ceilometer (Morris 2016) and microwave radiometer (MWR; Morris 2006) measurements are also used in the processing of the data from both sites.

Cloud occurrence is determined on an hourly basis to match the temporal resolution of the models $(1 \mathrm{~h}$, except for AMPS at the WAIS Divide, which has a temporal resolution of $3 \mathrm{~h}$ ). An hour is considered cloudy if the hourly cloud occurrence fraction is above $25 \%$ ( $15 \mathrm{~min}$ ), and clear otherwise. Similarly, a cloudy hour is considered as containing liquid-bearing cloud layers (LBCLs; likely mixed-phase clouds) if the detected liquid occurrence fraction is above $25 \%$, and containing only ice clouds otherwise. The LBCLs are classified as opaque when the hourly mean liquid water path (LWP) is higher than $25 \mathrm{~g} \mathrm{~m}^{-2}$, and tenuous otherwise. Clouds with LWP exceeding this value act similar to blackbody emitters in the longwave (LW; Shupe and Intrieri 2004, Fig. 6; Turner et al. 2007b, Fig. SB1). The LWP is retrieved using the MWR measurements (Cadeddu et al. 2007; Turner et al. 2007a), or with the combined data product of the MWR and the G-Band Vapor Radiometer Profiler (GVRP; Cadeddu 2010; Cadeddu et al. 2009), when measurements from both instruments are available. Due to the dependence on the LWP retrievals in the determination of the atmospheric regime (clear sky, tenuous LBCLs, etc.), only periods with MWR data are considered for the LW $\downarrow$ radiation comparison; that is, FebruaryDecember 2016 (11 months) at McMurdo Station, and 19 December 2015-17 January 2016 at the WAIS Divide. 
The LW $\downarrow$ data are based on the sky radiation radiometers (SKYRAD; Andreas et al. 2018) measurements, the instruments of which were deployed at both sites throughout the campaign. Finally, we also utilize the twice-daily and four-times-daily radiosonde measurements at McMurdo (from the entire year of 2016) and the WAIS Divide (from 6 December 2015-17 January 2016), respectively, to compare various atmospheric parameter profiles with the output from the models. Both the sounding and model data are linearly interpolated up to $6 \mathrm{~km}$ in $100-\mathrm{m}$ intervals for all statistics presented in this study.

\section{b. AMPS}

AMPS is an operational Antarctic weather prediction model that is based on the Polar Weather Research and Forecasting (WRF) Model (Hines and Bromwich 2008), and is the result of a joint collaboration between the National Center for Atmospheric Research (NCAR) and the Polar Meteorology Group at The Ohio State University's Byrd Polar and Climate Research Center. The Polar-WRF version on which AMPS is based on was upgraded from version 3.3.1 to version 3.7.1 on 19 January 2016; hence, the entire WAIS deployment period is covered by the earlier version, while most of the McMurdo deployment (including the full LW $\downarrow$ dataset used here) is supported by the newer version of Polar WRF. AMPS currently utilizes WRF's computationally efficient single-moment 5-class microphysics scheme (WSM5), which considers cloud water that is allowed to be supercooled, cloud ice, rain, and snow, and operates on the resolved wind fields (see Hong et al. 2004).

AMPS forecasts are initiated twice daily at 0000 and 1200 UTC, using initial and lateral boundary conditions from the National Centers for Environmental Prediction (NCEP) Global Forecast System (GFS). We use the AMPS data after a model spinup of $12 \mathrm{~h}$. The data for McMurdo Station and the WAIS Divide are bilinearly interpolated from AMPS domains 5 and 2 (Powers et al. 2012, Fig. 2), which have a spatial resolution of $\sim 1.1$ and $\sim 10 \mathrm{~km}$, and are provided in intervals of 1 and $3 \mathrm{~h}$, respectively.

\section{c. ERA5}

ERA5 is the fifth-generation ECMWF reanalysis model and is the successor of ERA-Interim (Dee et al. 2011). The cloud and large-scale precipitation processes are described in ERA5 by prognostic equations for cloud water and ice, rain, snow, and cloud fraction. The model considers various sources and sinks of all cloud variables, and provides better physical representation of supercooled liquid water and mixed-phase clouds relative to ERA-Interim (see ECMWF 2016, chapter 7; Tiedtke 1993). The full list of improvements in ERA5 with respect to ERA-Interim can be found in Hersbach and Dee (2016). While ERA5 integrated atmospheric water amount and LW $\downarrow$ prediction performance over Antarctica have not been reported to our knowledge, previous studies did find a better agreement of ERAInterim with Antarctic measurements relative to other reanalysis models (e.g., Lenaerts et al. 2017; Wang and Dickinson 2013).

ERA5 provides hourly output data at a spatial resolution of up to $0.25^{\circ}$ (used here), which corresponds to $\sim 23.4 \mathrm{~km}$ in the north-south direction and $\sim 5.8$ and $\sim 5.1 \mathrm{~km}$ in the east-west direction at the latitudes of McMurdo Station and the WAIS Divide, respectively. The ERA5 LW $\downarrow$ data are taken from the model forecast fields (initialized at 0600 and 1800 UTC) while allowing $3 \mathrm{~h}$ of model spinup. All the ERA5 data in this study are bilinearly interpolated to the coordinates of McMurdo Station and the WAIS Divide. While the adjacent ERA5 grid cells used for the bilinear interpolation over McMurdo are clear of the two volcanoes to the northnortheast (no surface-altitude biases in the data), the model performance is strongly influenced by the nearby topography. This is evident by the better LW $\downarrow$ agreement with the observations at McMurdo Station (but not at the WAIS Divide) when the bilinear interpolation is used (not shown). This improvement results from the inclusion of grid cells located farther away from the topographic features of Ross Island into the estimate.

\section{Results}

\section{a. Model LW $\downarrow$ bias}

Figure 1 shows the model error (model minus observation) frequency of occurrence in both AMPS and ERA5 at McMurdo Station and the WAIS Divide during four different observed regimes, namely, the occurrence of cloud-free periods (clear sky), ice clouds (no liquid), tenuous LBCLs, and opaque LBCLs. This figure is complemented by Table 1 , which provides error statistics for each of the models, sites, and regimes. These statistics include the error percentiles, mean, $\mathrm{SD}$, and $r$ between the observations and the models. The value of $r$ is also calculated for the deseasonalized data at McMurdo, that is, the residual data after the removal of the annual cycle of the LW $\downarrow$, which is estimated using a nonlinear least squares fit of sine with a periodicity of 365.25 days. This calculation is not performed over the WAIS Divide due to the short dataset (30 days).

Both models show a negative bias (LW $\downarrow$ less than that observed) at both sites when the full datasets are 

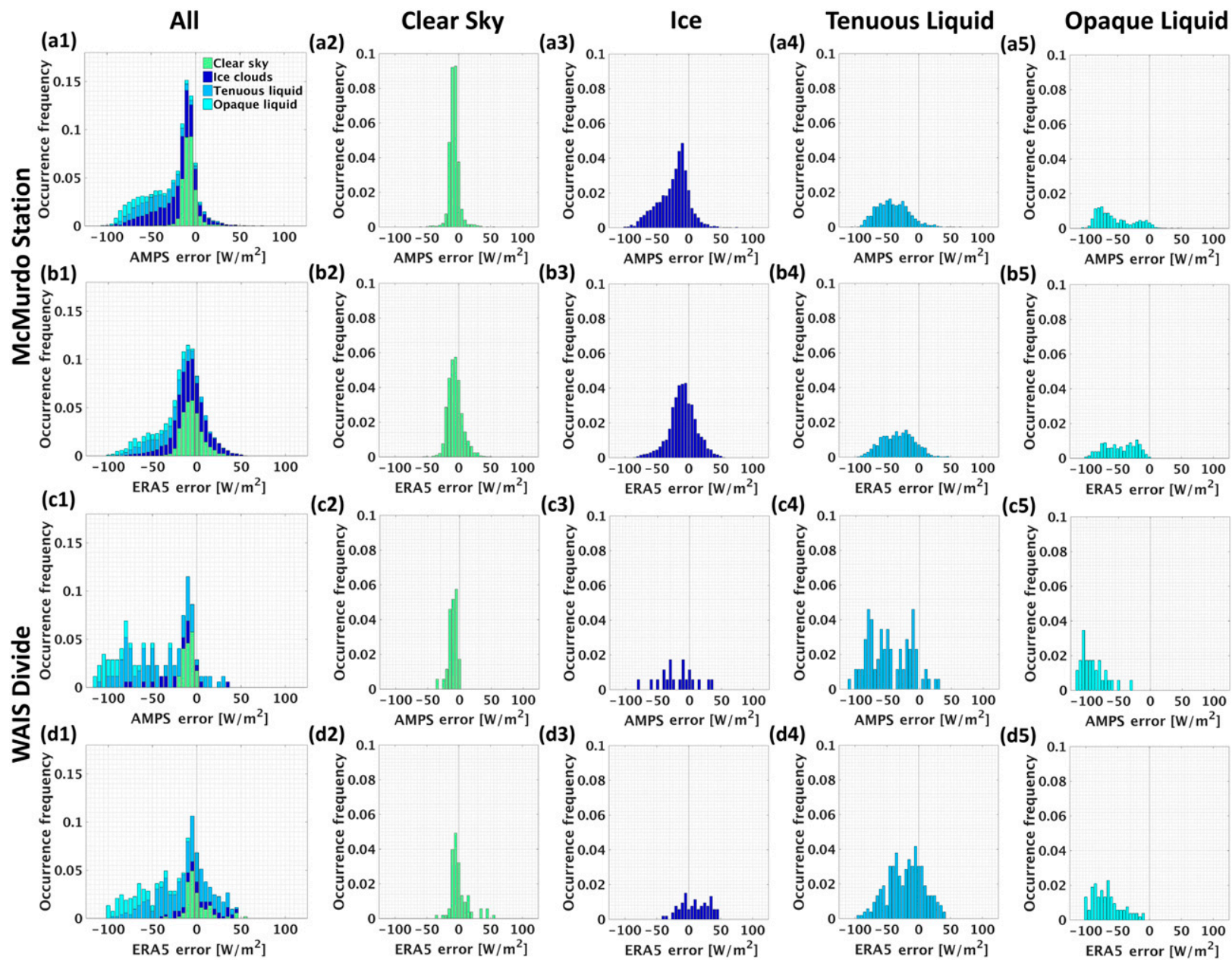

(c3)
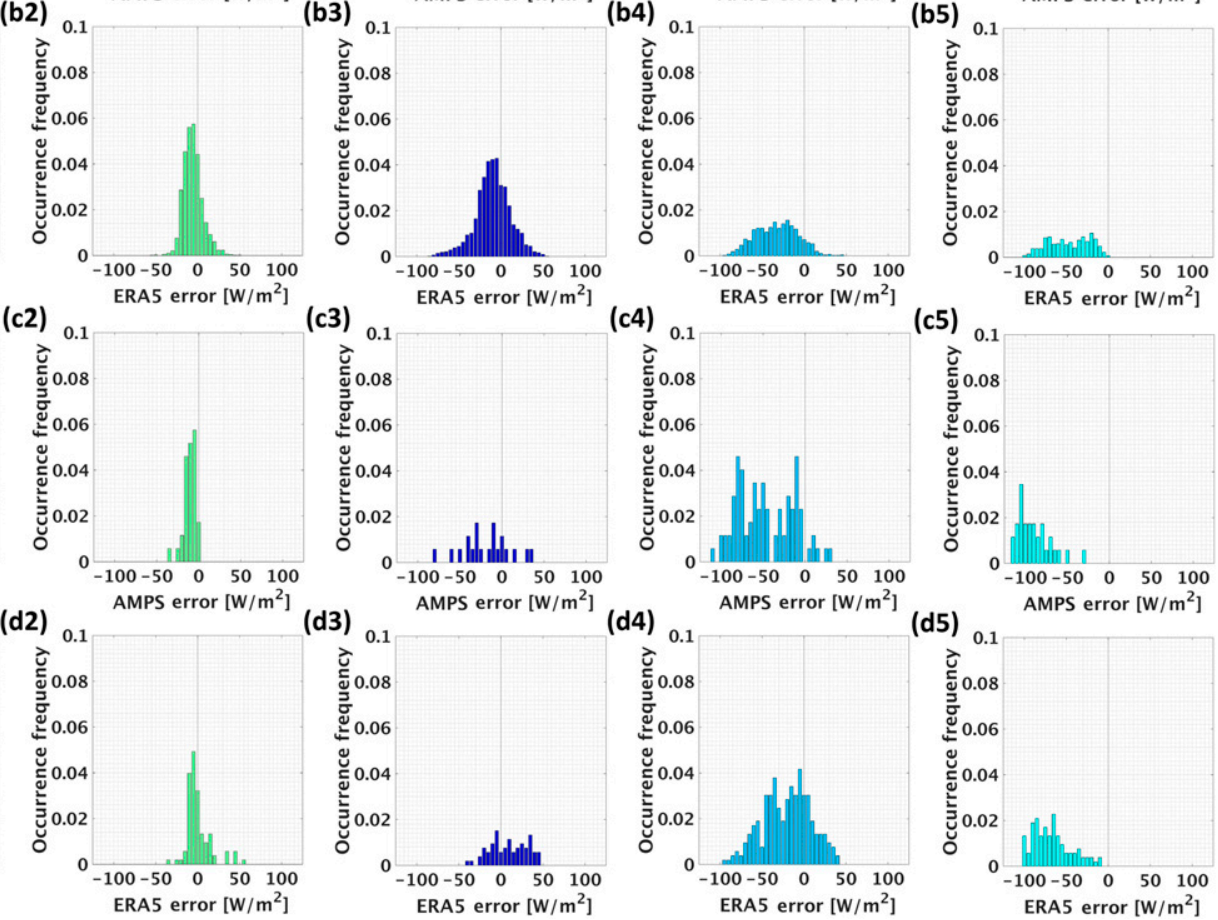

FIG. 1. AMPS and ERA5 LW $\downarrow$ model error (model minus observation) at (a),(b) McMurdo Station and (c),(d) the WAIS Divide. (column 1) Error occurrence frequency for the full datasets, partitioned into the occurrence of cloud-free periods (clear sky), ice clouds, tenuous LBCLs, and opaque LBCLs (see legend). (columns 2-5) Error occurrence frequencies for clear sky and the three cloud types are depicted separately to make them easier to evaluate.

considered, in agreement with several previous reports (cf. Bromwich et al. 2013; Fréville et al. 2014; Lenaerts et al. 2017). The relative occurrence of each atmospheric regime during the two deployment periods controls the magnitude of these total biases. The occurrence of these atmospheric regimes is influenced by the regional synoptic conditions, which were fairly representative of their long-term patterns for the periods corresponding with the AWARE deployment dates at each site (Silber et al. 2019). However, other factors also influence the locally observed atmospheric regimes, for example, mesoscale forcing, sea ice extent, and atmospheric rivers (e.g., Carrasco and Bromwich 1993; Scott and Lubin 2014, Fig. 17; Silber et al. 2019). Therefore, the magnitude of the total-mean biases for the AWARE-deployment periods may vary from the values reported in Table 1.
The full dataset SD $>26 \mathrm{~W} \mathrm{~m}^{-2}$ (in both models at both sites) and the $r$ values for the full McMurdo datasets are comparable with previous reports (see section 1). However, the $r$ values of the model output for the WAIS Divide are much lower, partially as a result of the smaller number of samples. The smaller differences in $r$ during cloudy periods between the raw and the deseasonalized data in both models relative to the clearsky instances suggest that the observed biases are largely due to cloud properties, and do not show a significant dependence on the annual temperature cycle. This conclusion is supported by the fact that results from a seasonal analysis (based on months; not shown) both correspond with the annual statistics discussed below and are similar for different seasons. The observed seasonal variabilities are related to the observed cloud properties. For example, both models exhibit exceptionally 
TABLE 1. AMPS and ERA5 LW $\downarrow$ model-error statistics during different atmospheric regimes at McMurdo Station and the WAIS Divide. The Pearson's correlation coefficient $r$ is calculated for the raw data at both sites, as well as for the residual data (at McMurdo), after the removal of the annual cycle using a nonlinear least squares sine fit.

\begin{tabular}{|c|c|c|c|c|c|c|c|c|c|c|}
\hline \multirow[b]{2}{*}{ Model } & \multirow[b]{2}{*}{ Atmospheric regime } & \multicolumn{5}{|c|}{ Percentiles $\left(\mathrm{W} \mathrm{m}^{-2}\right)$} & \multirow[b]{2}{*}{ Mean $\left(\mathrm{W} \mathrm{m}^{-2}\right)$} & \multirow[b]{2}{*}{$\mathrm{SD}\left(\mathrm{W} \mathrm{m}^{-2}\right)$} & \multirow[b]{2}{*}{$r$} & \multirow[b]{2}{*}{$r$ (no annual) } \\
\hline & & 5 & 25 & 50 & 75 & 95 & & & & \\
\hline \multicolumn{11}{|c|}{ McMurdo Station } \\
\hline \multirow{5}{*}{ AMPS } & Clear sky & -14.5 & -9.0 & -5.0 & -1.1 & 8.2 & -3.6 & 15.9 & 0.86 & 0.66 \\
\hline & Ice & -65.5 & -36.0 & -16.2 & -5.7 & 12.3 & -21.0 & 24.0 & 0.76 & 0.70 \\
\hline & Tenuous LBCL & -75.7 & -56.8 & -40.3 & -21.2 & 3.6 & -37.7 & 27.7 & 0.68 & 0.55 \\
\hline & Opaque LBCL & -86.0 & -75.6 & -61.1 & -31.9 & 1.5 & -51.8 & 30.6 & 0.65 & 0.62 \\
\hline & Total & -74.8 & -41.5 & -13.5 & -4.4 & 8.6 & -22.6 & 28.4 & 0.76 & 0.67 \\
\hline \multirow{5}{*}{ ERA5 } & Clear sky & -18.9 & -11.0 & -3.9 & 3.2 & 19.4 & -2.1 & 18.1 & 0.81 & 0.61 \\
\hline & Ice & -43.4 & -18.7 & -6.9 & 6.1 & 27.7 & -6.9 & 21.0 & 0.82 & 0.80 \\
\hline & Tenuous LBCL & -70.3 & -49.3 & -29.9 & -12.0 & 10.9 & -29.4 & 27.7 & 0.69 & 0.62 \\
\hline & Opaque LBCL & -85.5 & -66.4 & -43.6 & -21.8 & -8.0 & -43.7 & 27.0 & 0.68 & 0.69 \\
\hline & Total & -65.9 & -25.6 & -10.5 & 0.8 & 21.0 & -14.1 & 26.8 & 0.79 & 0.74 \\
\hline \multicolumn{11}{|c|}{ WAIS Divide } \\
\hline \multirow{5}{*}{ AMPS } & Clear sky & -16.4 & -10.4 & -5.8 & -2.6 & 1.9 & -6.4 & 5.2 & 0.94 & - \\
\hline & Ice & -77.4 & -38.1 & -20.0 & -7.0 & 22.8 & -23.7 & 28.1 & 0.53 & - \\
\hline & Tenuous LBCL & -90.4 & -71.4 & -45.9 & -11.8 & 15.2 & -41.2 & 34.0 & 0.30 & - \\
\hline & Opaque LBCL & -110.4 & -104.0 & -91.8 & -77.3 & -48.8 & -87.7 & 20.1 & 0.06 & - \\
\hline & Total & -104.0 & -75.9 & -37.9 & -9.0 & 6.8 & -41.8 & 37.6 & 0.33 & - \\
\hline \multirow{5}{*}{ ERA5 } & Clear sky & -10.8 & -5.2 & -1.2 & 6.6 & 39.0 & 3.1 & 14.3 & 0.64 & - \\
\hline & Ice & -22.4 & -9.1 & 4.8 & 22.8 & 43.0 & 7.3 & 21.7 & 0.72 & - \\
\hline & Tenuous LBCL & -64.2 & -36.2 & -13.1 & 5.3 & 33.2 & -15.1 & 29.5 & 0.46 & - \\
\hline & Opaque LBCL & -97.1 & -81.5 & -68.8 & -54.4 & -21.2 & -65.2 & 22.4 & 0.36 & - \\
\hline & Total & -83.7 & -43.0 & -10.8 & 4.2 & 34.6 & -19.3 & 34.8 & 0.47 & - \\
\hline
\end{tabular}

high SD values in spring season (September-November) during observed clear-sky and LBCL periods (higher than 24 and $36 \mathrm{~W} \mathrm{~m}^{-2}$, respectively). These higher values likely ensue from the combination of the low occurrence and predominantly shallower clouds relative to the other seasons (see Figs. 4, 6, and 9 in Silber et al. 2018a), which could impact the model performance (see section 4).

AMPS predominantly underestimates the LW $\downarrow$ at both sites and in all regimes. The AMPS histograms in Figs. 1a and 1c display a strong tendency for negative values. Some $\mathrm{LW} \downarrow$ overestimation instances do occur, mainly in clear-sky and ice-cloud periods, but these are hardly noticeable when the full datasets are considered. For example, the $\mathrm{LW} \downarrow$ is underestimated at least up to the 75th percentile in all the regimes (Table 1).

AMPS LW $\downarrow$ in clear-sky periods is underestimated half of the time by more than $5 \mathrm{~W} \mathrm{~m}^{-2}$ and has a mean error of -3.6 and $-6.4 \mathrm{Wm}^{-2}$ at McMurdo and the WAIS, respectively. However, $r>0.86$ at both sites, and has a reasonable value even with the annual cycle removed, which suggests that moisture advection patterns to both sites are well captured but underestimated in amplitude (supported by precipitable water vapor comparison; not shown).

During cloudy periods, AMPS shows poorer performance in $\mathrm{LW} \downarrow$ prediction $\left(\mathrm{SD}>20 \mathrm{~W} \mathrm{~m}^{-2}\right.$ ), with greater underestimation values. The tendency for LW $\downarrow$ underestimation is emphasized during LBCL occurrences (Figs. 1a4,a5,c4,c5), especially in the opaque cases, with mean biases below $-51 \mathrm{~W} \mathrm{~m}^{-2}$ at both sites.

ERA5 shows in general a tendency for model LW $\downarrow$ underestimation as well, but with more overestimation occurrences than AMPS (Figs. 1b,d). Clear-sky periods are rather variable, with SD values above $14 \mathrm{~W} \mathrm{~m}^{-2}$ at both sites. The LW $\downarrow$ during these periods is mostly underestimated (negative medians in Table 1), while the mean $\mathrm{LW} \downarrow$ is negative at McMurdo and positive at the WAIS. The different mean and median signs suggest that the overestimation error magnitudes at the WAIS (on the order of a few tens of watts per square meter) are larger than the underestimation error magnitudes (see Fig. $1 \mathrm{~d} 2$ and the matching percentiles in Table 1).

ERA5 also tends to underestimate the $\mathrm{LW} \downarrow$ when ice clouds are observed at McMurdo (median LW $\downarrow$ of $-6.9 \mathrm{~W} \mathrm{~m}^{-2}$; Fig. 1b3), and overestimate at the WAIS (median LW $\downarrow$ of $4.8 \mathrm{~W} \mathrm{~m}^{-2}$; Fig. 1d3). Similar to the AMPS model comparison, the ERA5 LW $\downarrow$ biases are largest (at both sites) during the occurrence of LBCLs, with mean and median biases below $-43 \mathrm{~W} \mathrm{~m}^{-2}$ in opaque LBCL cases.

In multiple robustness tests using the McMurdo dataset, in which the hourly thresholds for the determination of cloud occurrence and type are modified, there are 
merely small changes in the clear-sky and cloudy period statistics presented in Table 1, except for the ice-cloud and tenuous-LBCL percentiles and mean biases (see Table S1 in the online supplemental material). These icecloud and tenuous-LBCL mean biases may increase by up to $\sim 20 \%$ and $60 \%$, respectively, when higher hourly thresholds are used, an increase that is attributed to the omission of short-lived, less "healthy," and optically thinner clouds from the analysis.

The notable magnitudes of the LW $\downarrow$ biases during LBCL occurrences (in both models), as well as the scale of the lower-percentile errors in ice-cloud instances (Table 1), are comparable to the instantaneous cloud radiative forcing of polar LBCL and ice clouds, respectively (e.g., Miller et al. 2015; Silber et al. 2019). Disparities of the modeled water quantities (and atmospheric temperature profiles) and lack of correspondence between the modeled and observed atmospheric regime could bring about these cloudy period biases and the large clear-sky variability discussed above, via changes in the atmospheric optical-depth profile and the effective LW brightness temperature of the sky. These disparities are examined below.

\section{b. Model atmospheric regime and hydrometeor amount errors}

Figure 2 presents scatterplots of the modeled versus observed LWP and ice water path (IWP) during modeled and observed cloud occurrence, together with $r$ and linear fits between the datasets. The thresholds used to determine model LBCL and ice-cloud occurrences are based on annual (2016) statistics from the AWARE campaign (not shown). The threshold values are set to the 1st percentile of the observed LWP $\left(1 \mathrm{~g} \mathrm{~m}^{-2}\right)$ and IWP $\left(10^{-3} \mathrm{~g} \mathrm{~m}^{-2}\right)$ values. The IWP comparison is only made for McMurdo Station because the IWP retrievals (following Hogan et al. 2006) are based on radar measurements, which were not performed at the WAIS deployment.

Figure 3 shows the atmospheric regime correspondence between the model and the observations at both sites. The modeled atmospheric regimes are calculated with the same thresholds that are mentioned above. This table is divided into two sections: the left section gives the correspondence percentages relative to the number of observed cases per atmospheric regime. For example, the observed clear-sky periods at McMurdo were determined by AMPS as clear sky, ice cloud, and LBCL occurrence in $45.72 \%, 54.15 \%$, and $0.13 \%$ of the time, respectively (together, $100 \%$ of observed clearsky occurrences). The percentages in the right section are calculated relative to the number of modeled cases per atmospheric regime. For example, the AMPS modeled clear-sky periods at McMurdo were actually
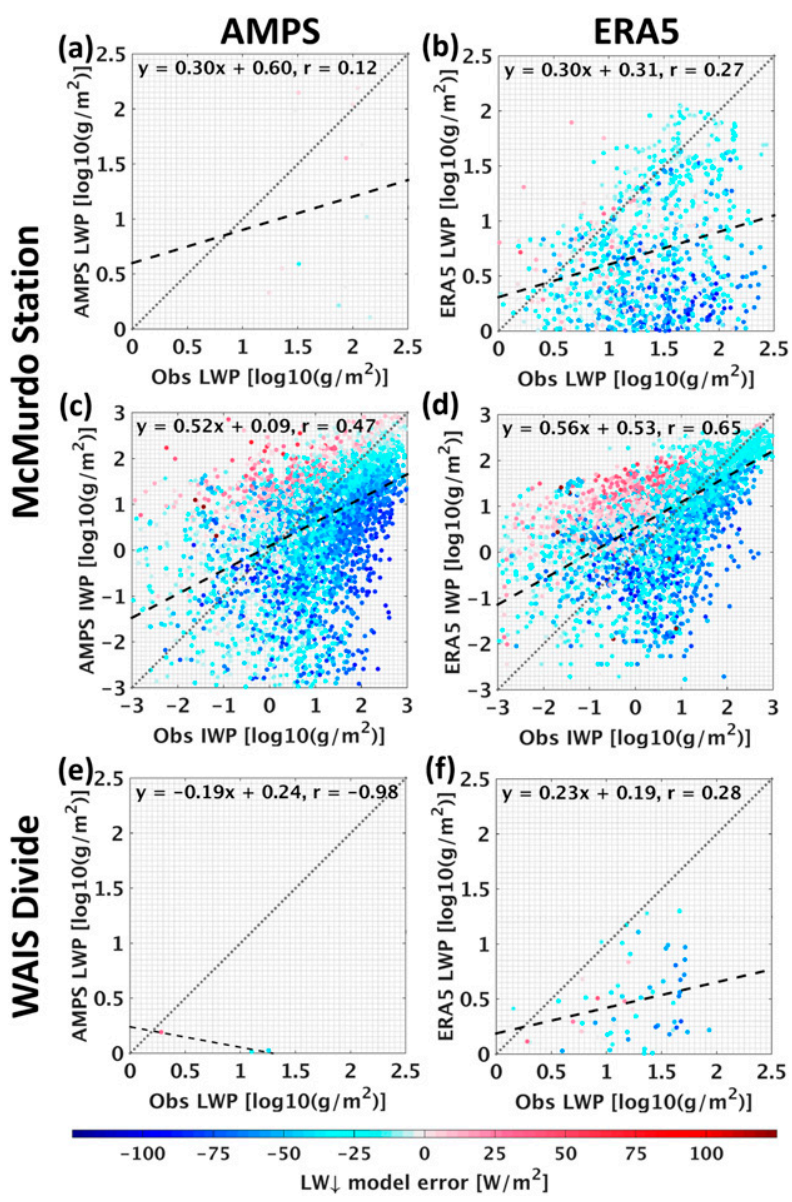

FIG. 2. (left) AMPS and (right) ERA5 LWP and IWP model output vs the observations at (a)-(d) McMurdo Station and (e),(f) the WAIS Divide. The illustrated LWP and IWP data are based only on periods when both the observations and the model indicate the occurrence of LBCLs and ice clouds, respectively. The marker colors represent the LW $\downarrow$ model errors. The dotted gray lines designate the 1:1 correspondence lines. The dashed black lines denote least squares linear fits of the modeled as a function of the observed parameters. Linear fit coefficients and the Pearson's correlation coefficient $r$ (statistically significant for all IWP panels, and the ERA5 LWP at McMurdo) are given at the top of each panel. The IWP is compared only at McMurdo Station because the retrieval of this parameter is based on radar measurements, which were not performed at the WAIS Divide.

clear sky, ice cloud, and LBCL occurrence periods $55.63 \%, 23.18 \%$, and $21.20 \%$ of the time, respectively (together, $100 \%$ of the clear-sky periods based on AMPS).

The small number of samples in the AMPS LWP plots (Figs. 2a,e) are the result of the model producing LBCLs for less than $2.5 \%$ of the cases LBCLs are observed (Fig. 3, left section). Instead, the model tends to generate only ice clouds on at least $80 \%$ of the LBCL occurrences, which may occasionally compensate for the lack of liquid in the resolved LW $\downarrow$ (not shown). On the other hand, 


\begin{tabular}{|c|c|c|c|c|c|c|c|c|}
\hline \multirow[t]{2}{*}{ Site } & \multirow[t]{2}{*}{ Model } & \multirow{2}{*}{$\begin{array}{l}\text { Atmospheric Regime (rows - } \\
\text { model, columns - observations) }\end{array}$} & \multicolumn{3}{|c|}{$\begin{array}{l}\% \text { relative to the total number of observed cases } \\
\text { per atmospheric regime }\end{array}$} & \multicolumn{3}{|c|}{$\begin{array}{l}\% \text { relative to the total number of modeled cases } \\
\text { per atmospheric regime }\end{array}$} \\
\hline & & & Clear sky & ice clouds & $\mathrm{LBCL}$ & Clear sky & ice clouds & $\mathrm{LBCL}$ \\
\hline \multirow{6}{*}{ 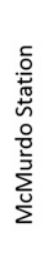 } & \multirow{3}{*}{ AMPS } & Clear sky & $45.72 \%$ & $15.16 \%$ & $16.58 \%$ & $55.63 \%$ & $23.18 \%$ & $21.20 \%$ \\
\hline & & Ice cloud & $54.15 \%$ & $84.70 \%$ & $82.89 \%$ & $21.84 \%$ & $42.98 \%$ & $35.18 \%$ \\
\hline & & $\mathrm{LBCL}$ & $0.13 \%$ & $0.14 \%$ & $0.53 \%$ & $15.00 \%$ & $20.00 \%$ & $65.00 \%$ \\
\hline & \multirow{3}{*}{ ERA5 } & Clear sky & $18.19 \%$ & $2.39 \%$ & $2.08 \%$ & $77.98 \%$ & $12.84 \%$ & $9.17 \%$ \\
\hline & & Ice cloud & $54.97 \%$ & $76.01 \%$ & $58.57 \%$ & $25.92 \%$ & $45.04 \%$ & $29.03 \%$ \\
\hline & & $\mathrm{LBCL}$ & $26.84 \%$ & $21.60 \%$ & $39.35 \%$ & $28.17 \%$ & $28.48 \%$ & $43.35 \%$ \\
\hline \multirow{6}{*}{ 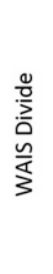 } & \multirow{3}{*}{ AMPS } & Clear sky & $60.00 \%$ & $15.79 \%$ & $17.60 \%$ & $41.86 \%$ & $6.98 \%$ & $51.16 \%$ \\
\hline & & Ice cloud & $40.00 \%$ & $84.21 \%$ & $80.00 \%$ & $9.38 \%$ & $12.50 \%$ & $78.13 \%$ \\
\hline & & $\mathrm{LBCL}$ & $0.00 \%$ & $0.00 \%$ & $2.40 \%$ & $0.00 \%$ & $0.00 \%$ & $100.00 \%$ \\
\hline & \multirow{3}{*}{ ERA5 } & Clear sky & $20.00 \%$ & $0.00 \%$ & $2.08 \%$ & $69.23 \%$ & $0.00 \%$ & $30.77 \%$ \\
\hline & & Ice cloud & $65.56 \%$ & $94.34 \%$ & $81.25 \%$ & $14.01 \%$ & $11.88 \%$ & $74.11 \%$ \\
\hline & & $\mathrm{LBCL}$ & $14.44 \%$ & $5.66 \%$ & $16.67 \%$ & $16.25 \%$ & $3.75 \%$ & $80.00 \%$ \\
\hline
\end{tabular}

FIG. 3. AMPS and ERA5 atmospheric regime correspondence with the observations at McMurdo Station and the WAIS Divide. The percentages in the left section are given relative to the total number of observed cases per atmospheric regime (i.e., the sum of vertical cell triplets equals $100 \%$ ), whereas in the right section, the percentages are relative to the total number of modeled cases per atmospheric regime (i.e., the sum of horizontal cell triplets equals $100 \%$ ). The model thresholds for ice-cloud and LBCL hourly occurrences are LWP $\geq$ $1 \mathrm{~g} \mathrm{~m}^{-2}$ and IWP $\geq 10^{-3} \mathrm{gm}^{-2}$, respectively (see text for details).

the model does not tend to produce LBCLs when they are not observed. The AMPS tendency to overproduce ice clouds is also seen during clear-sky periods, with the model producing ice clouds during $\sim 54 \%$ and $40 \%$ of the observed clear-sky hours at McMurdo and the WAIS, respectively. The lower percentage at the WAIS may explain the higher $r$ during clear-sky periods (see Table 1). The periods when the model generates only ice clouds without being observed account for more than $57 \%$ and $87 \%$ of the total model-produced "pure" ice-cloud cases at McMurdo and the WAIS, respectively (Fig. 3, right section).

Given AMPS tendency to overproduce clouds, it comes as no surprise that "pure" ice-cloud occurrence is well captured by AMPS. The modeled ice clouds are present in more than $84 \%$ of the time these clouds are observed and have some IWP correspondence with the observations, especially at higher values (Fig. 2c). Some tendency for $\mathrm{LW} \downarrow$ underestimation is found when the model predicts IWPs that are too small relative to the observations. Conversely, the LW $\downarrow$ tends to be overestimated when the model exaggerates the IWP (with values predominantly higher than $10 \mathrm{~g} \mathrm{~m}^{-2}$; see Fig. 2c).

ERA5 lacks an LWP correlation with the observations at both sites (Figs. 2b,f) and has a tendency to underestimate the observed LWP by up to two orders of magnitude (most markers are below the 1:1 correspondence line). The model LWP values rarely exceed $\sim 100 \mathrm{~g} \mathrm{~m}^{-2}$, despite numerous observations of higher values (at McMurdo).

Similar to AMPS, ERA5 tends to generate ice clouds instead of LBCLs more than 58\% of the time (Fig. 3, left section), which can reduce the LW $\downarrow$ errors (not shown). Relative to the total model production of liquid, liquid is incorrectly produced (during ice-cloud or clear-sky conditions) in more than $56 \%$ of the time at McMurdo, but only $20 \%$ of the time at the WAIS (Fig. 3, right section).

Ice clouds are frequently produced by ERA5 and have a reasonable IWP agreement with the observations (Fig. 2d). Similar to AMPS, ERA5 tends to underestimate (overestimate) the LW $\downarrow$ when its IWP values are too low (high) relative to the observations. While ERA5 captures $\sim 76 \%$ and $\sim 94 \%$ of the observed ice-cloud occurrences at McMurdo and the WAIS, these cases only account for $\sim 45 \%$ and $\sim 12 \%$ of the model "pure" ice-cloud periods, respectively.

ERA5 also tends to generate hydrometeors (mainly ice) when clear-sky conditions are observed (more than $80 \%$ of the time, at both sites). These instances govern the larger magnitude of the positive (relative to the negative) LW $\downarrow$ errors during observed clear-sky conditions (see section 3a). We see the same result, although to a much smaller extent (Fig. 1a2), with AMPS at McMurdo.

The LW $\downarrow$ when both the models and the observations describe clear-sky conditions is consistently underestimated (at least up to the 88th percentile; mean magnitudes $>4.8 \mathrm{~W} \mathrm{~m}^{-2}$ and SDs smaller than the mean magnitudes; see Table S2 in the online supplemental material). This conspicuous clear-sky bias, the rarely produced LBCLs (with deficient LWP; see Figs. 2a,b,e,f and Fig. 3, left section), and the excess generation of ice clouds relative to the observations (Fig. 3, right section) 


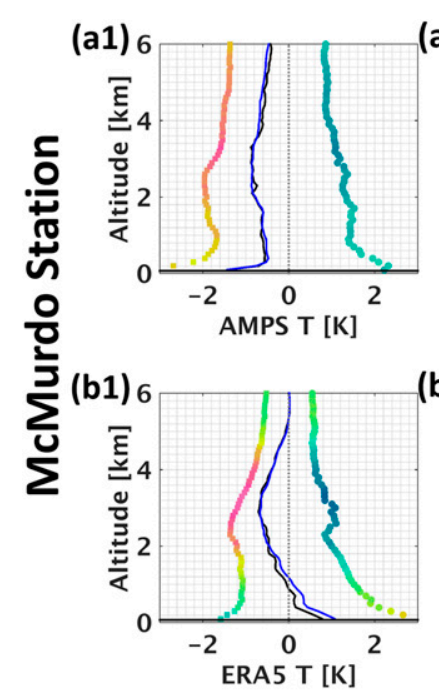

(a2) 6

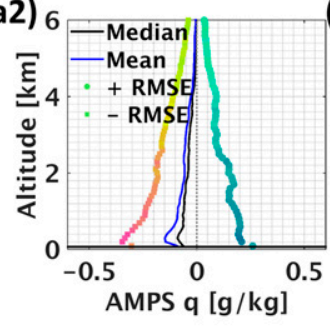

(a3)

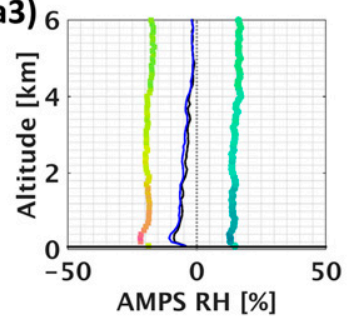

(b2) 6

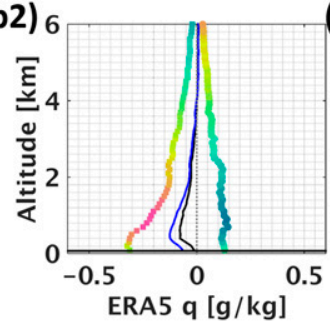

(b3) 6

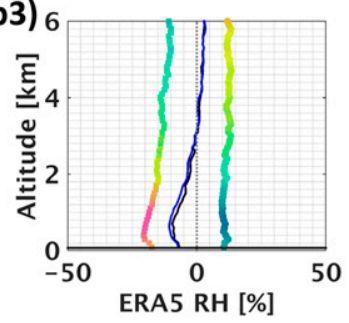

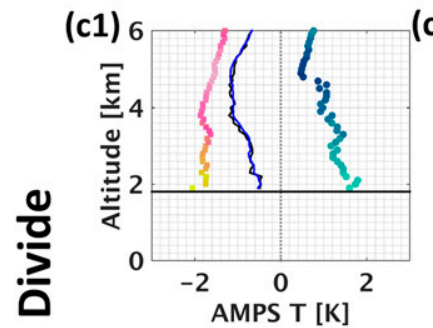

(c2) 6

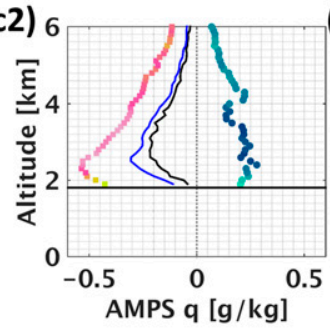

(c3) 6

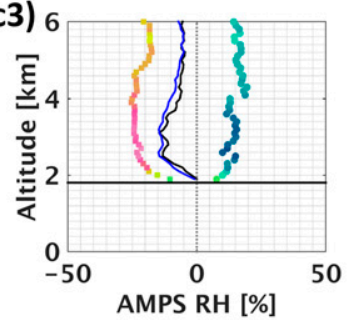

$\frac{1}{\zeta}(d 1)$

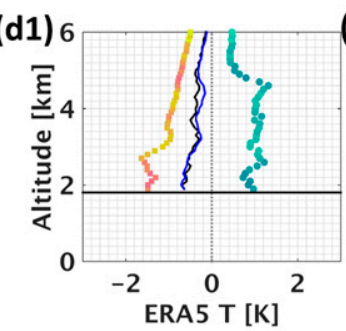

(d2)

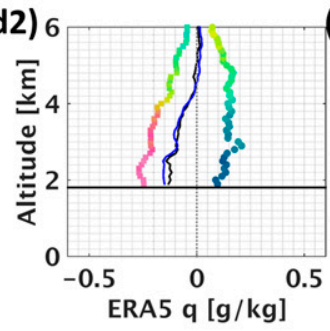

(d3)

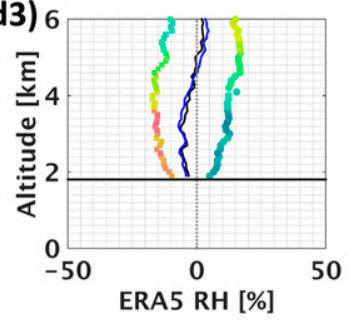

0

10
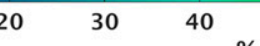

FIG. 4. Modeled profile biases of (from left to right) the temperature, water vapor mixing ratio $q$, and relative humidity $(\mathrm{RH})$. The black and blue curves designate the median and mean biases, respectively. The square and circle markers to the left and right of the mean curves denote the RMSE of the model under and overestimation cases, respectively, where the model underestimation RMSEs are multiplied by -1 to distinguish them from model overestimation cases. The colors represent the percentage of the data samples that are under- or overestimated, such that the percentage sum of the model under- and overestimated cases at a given altitude equals to $100 \%$. The thick horizontal black line designates the surface altitude. This comparison is only based on hours where radiosonde measurements were made.

suggest that the models inaccurately capture the atmospheric temperature and water vapor profiles.

\section{c. Atmospheric temperature and water vapor errors}

Figure 4 depicts the profiles of the mean (solid blue) and median (solid black) model errors of the temperature $T$, specific humidity $q$, and relative humidity $(\mathrm{RH})$. The model $\mathrm{RH}$ and the observed $q$ are calculated using the saturation vapor pressure equation provided by Murphy and Koop (2005). The markers represent the root-mean-square errors (RMSEs) of the under- and overestimated cases, where the model underestimation RMSEs are multiplied by -1 to distinguish them from model overestimation cases. The marker colors 
designate the percentage of the under- and overestimated cases at each altitude. AMPS tends to form an atmosphere that is too cold and dry relative to the observations (Figs. 4a1,a2,c1,c2; see also Hines et al. 2019), which may also explain the tendency to produce smaller amounts of ice (Fig. 2c). The largest $T$ bias at McMurdo (Fig. 4a1) is observed near the surface (mean and median values of $-1.4 \mathrm{~K}$ ), in agreement with Bromwich et al. (2013, their Fig. 9). This near-surface bias suggests that the model produces too frequent and/ or too strong surface $T$ inversions, which correspond with potentially more and/or stronger surface $q$ inversions (Fig. 4a2). These low-level $T$ and $q$ biases in AMPS (seen both in clear sky and cloudy conditions; see Fig. S1 in the supplemental material) are likely related to high near-surface wind speed intensities originated from katabatic flow along the Ross Ice Shelf (see Wille et al. 2016, 2017).

The $q$ profiles in the model show a negative bias that is most pronounced below $2.5 \mathrm{~km}$ (Fig. 4a2). This bias is reflected in underestimation of $\mathrm{RH}$ by averages of at least $4 \%$ (with a maximum negative RMSE of $\sim 22 \%$ ) up to $\sim 2 \mathrm{~km}$ (Fig. $4 \mathrm{a} 3$ ). The $q$ impact on the $\mathrm{RH}$ is moderated above $2 \mathrm{~km}$ by the large magnitude of the negative $T$ bias $(\sim 0.7-0.9 \mathrm{~K}$ on average, up to $\sim 4.5 \mathrm{~km}$ ). However, $\mathrm{RH}$ continues to be underestimated up to $\sim 8 \mathrm{~km}$ (not shown). It should be noted that the generally decreasing (with altitude) $q$ biases and RMSEs (as seen in the other $q$ panels as well; Figs. $4 \mathrm{~b} 2, \mathrm{c} 2, \mathrm{~d} 2$ ) are the result of the decreasing $T$ with altitude (e.g., Fig. 5 in Silber et al. 2018a), following the Clausius-Clapeyron equation.

At the WAIS Divide, the $T$ bias $(>1 \mathrm{~K})$ at the altitude range of $\sim 3.7-5.3 \mathrm{~km}$ is the result of consistent $(>75 \%$ of the time) $T$ underestimation with negative RMSEs of more than $1.4 \mathrm{~K}$ (Fig. 4c1). Higher negative RMSEs are observed near the surface, but relatively higher $T$ overestimation occurrences with high RMSEs $(>1.5 \mathrm{~K})$ mitigate the mean $T$ bias. Similar to McMurdo, the $q$ bias peaks at lower altitudes than the $T$ bias (maximum mean and median magnitudes of 0.31 and $0.21 \mathrm{~g} \mathrm{~kg}^{-1}$ at $\sim 2.5 \mathrm{~km}$, respectively; Fig. $4 \mathrm{c} 2$ ). The combined negative $q$ and $T$ biases are projected in the mean RH bias, which exceeds $10 \%$ from $\sim 2.5$ to $\sim 4 \mathrm{~km}$, and stays higher than $5 \%$ up to an altitude of $\sim 6 \mathrm{~km}$ (Fig. $4 \mathrm{c} 3$ ).

The lower resolution of ERA5 raised some initial concerns regarding the model's ability to capture the surface and atmospheric variability at McMurdo Station. That is, because of the complex local topography that results in a strong influence of mesoscale flow patterns in that region (Carrasco et al. 2003; Monaghan et al. 2005; Silber et al. 2019). However, examination of the ERA5 results in Fig. 4 (as well as in Figs. 1-3 and Table 1) reveals no clear signs of inferior model performance at McMurdo Station relative to the WAIS Divide.

ERA5 exhibits a negative $T$ bias from $\sim 1.1 \mathrm{~km}$ up to $\sim 5 \mathrm{~km}$ at McMurdo. This bias is emphasized from $2 \mathrm{~km}$ up to nearly $4 \mathrm{~km}$, with mean values $>0.4 \mathrm{~K}$ (Fig. $4 \mathrm{~b} 1$ ). This altitude range (where the $T$ bias peaks) has a large overlap with that of AMPS (Fig. 4a1). An overlap with AMPS is also observed in the altitude range where the magnitude of the $q$ bias is the highest (Figs. 4a2,b2). The $q$ bias in ERA5 reaches a maximum mean magnitude of $\sim 0.13 \mathrm{~g} \mathrm{~kg}^{-1}$ close to the surface, at $0.5 \mathrm{~km}$ (Fig. $4 \mathrm{~b} 2$ ). At these near-surface altitudes (below $1 \mathrm{~km}$ ) $T$ is overestimated by the model and maximizes near the surface with a mean bias of $\sim 1.1 \mathrm{~K}$ (Fig. $4 \mathrm{~b} 1$ ). The combination of the negative $q$ bias and positive $T$ bias yields negative $\mathrm{RH}$ bias magnitudes $>7 \%$ between the surface and $\sim 1 \mathrm{~km}$ (Fig. 4b3). The RH continues to be underestimated up to $\sim 3 \mathrm{~km}$ and is slightly overestimated (by $\sim 2 \%-3 \%$ ) above $3 \mathrm{~km}$.

The ERA5 $T$ profiles at the WAIS Divide display a negative bias that maximizes near the surface (mean of $-0.7 \mathrm{~K}$ ), and overall decreases in magnitude with height (Fig. 4d1). A similar bias pattern of a near-surface maximum $\left(-0.15 \mathrm{~g} \mathrm{~kg}^{-1}\right)$ and a decrease with height is observed in $q$ (Fig. 4d2). The $\mathrm{RH}$ values produced by the model are predominantly underestimated up to $4.5 \mathrm{~km}$ (magnitudes $>4 \%$ below $4 \mathrm{~km}$ ), and slightly overestimated above that altitude (Fig. 4d3).

Generally speaking, both models show the largest $T$, $q$, and RH RMSEs closer to the surface. Separation of the error calculation based on the atmospheric regime results in very similar error profiles (see Figs. S1 and S2 in the supplemental material), which emphasizes the consistency of these model errors. The negative biases stem both from the larger (in magnitude) and more frequent underestimation errors. The consistent negative $\mathrm{RH}$ errors below $3 \mathrm{~km}$ at McMurdo Station and $4 \mathrm{~km}$ at the WAIS Divide (Fig. 4, right panels), correspond with the altitudes where LBCLs are most frequently observed at these sites (Hines et al. 2019; Scott and Lubin 2016; Silber et al. 2018a). These RH errors, which are accentuated by their consistency and larger amplitudes in observed liquid-bearing vertical grid cells (see Figs. S1 and S2 in the supplemental material), are able to tip the scales between LBCL and clear-sky occurrence conditions, and can ultimately result in the large LW $\downarrow$ biases (section 3a).

To qualitatively examine the likelihood of liquid condensation in the models relative to the observations, we inspect the $\mathrm{RH}$ with respect to ice $\left(\mathrm{RH}_{\text {ice }}\right)$, calculated using the formulation in Murphy and Koop (2005). Figures 5a-f illustrate the cumulative distribution function $(\mathrm{CDF})$ of the observed and modeled $\mathrm{RH}_{\text {ice }}$ up to 

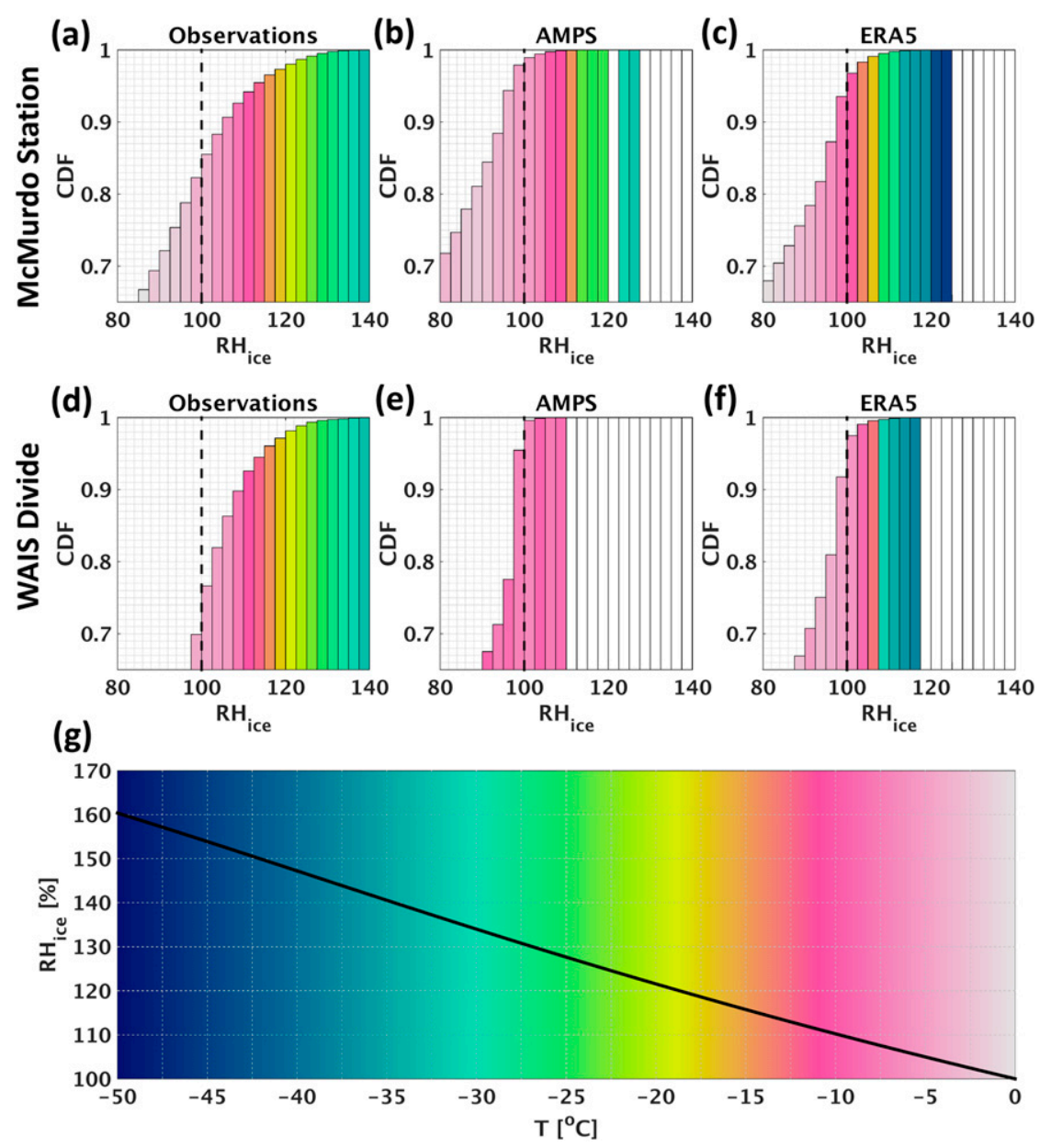

FIG. 5. (a)-(f) Observed and modeled CDF of $\mathrm{RH}$ with respect to ice $\left(\mathrm{RH}_{\mathrm{ice}}\right)$ between the surface and 6-km altitude (same altitude range that is shown in Fig. 4; bin width of $2.5 \%$ ). The bar colors designate the highest observed/modeled temperature in each $\mathrm{RH}_{\text {ice }}$ bin, following the temperature color representation depicted in $(\mathrm{g})$. White bars indicate zero bin counts. The dashed black lines denote $\mathrm{RH}_{\text {ice }}=100 \%$. $(\mathrm{g}) \mathrm{RH}_{\text {ice }}$ at water saturation.

$6 \mathrm{~km}$ (bin width of $2.5 \%$ ), together with the corresponding highest $T$ that is observed/modeled in every bin, which is designated by the bin color. The bins are colored in white when the total bin counts are equal to 0 . Figure $5 \mathrm{~g}$ shows $\mathrm{RH}_{\text {ice }}$ at water saturation.

The observations at both sites (Figs. 5a,d) exceed ice saturation in more than $14 \%$ and $23 \%$ of the data grid cells at McMurdo Station and the WAIS Divide, respectively, and exhibit high ice supersaturation values that extend slightly beyond $40 \%$, generally consistent with the observed occurrence of supercooled liquid. The highest temperatures at which these supersaturations are observed consistently correspond with the $\mathrm{RH}_{\text {ice }}$ at water saturation (Fig. $5 \mathrm{~g}$ ), and the cases where $\mathrm{RH}_{\text {ice }}$ is higher than $\mathrm{RH}_{\text {ice }}$ at water saturation fall within the $5 \%$ uncertainty range of the radiosonde $\mathrm{RH}$ measurement (Holdridge et al. 2011).
The $\mathrm{RH}_{\text {ice }}$ observations connote the limited ice nucleating particle (INP) concentrations in the West Antarctic atmosphere (e.g., Belosi et al. 2014), especially deposition-mode INP concentrations capable to nucleate ice and deplete atmospheric water vapor prior to liquid water condensation (e.g., de Boer et al. 2011). The models clearly do not exhibit the "ice-starved atmosphere" behavior apparent in observations. AMPS does show $\mathrm{RH}_{\text {ice }}$ values close to water saturation at supercooled temperatures, but only where $\mathrm{RH}_{\text {ice }}$ is $<110 \%$ (weakly supercooled) and these cases account for less than $1 \%$ of the data grid cells (Figs. 5b,e). ERA5 displays $\mathrm{RH}_{\text {ice }}$ that are significantly below $\mathrm{RH}_{\text {ice }}$ at water saturation (Figs. 5c,f). The presence of some liquid in the model can be attributed to the model's liquid generation schemes (ECMWF 2016, chapters 6 and 7.2.1). 
Based on the results presented here, we suggest that an overly dry atmosphere (see Fig. 4 and the higher CDF values at lower $\mathrm{RH}_{\text {ice }}$ in Fig. 5) leads to insufficient condensation of liquid, and evaporates existing liquid hydrometeors too quickly. The near-absence of ice supersaturation in the simulations provides further evidence that overproduction of ice in the models is driving water vapor concentrations to near-ice-saturated values, thereby desiccating the atmosphere via sedimentation. All of these processes may result in the large negative LW $\downarrow$ biases found in the models (which are emphasized during LBCL occurrence).

\section{Conclusions}

In this study, we examined the surface downwelling longwave radiation (LW $\downarrow$ ) biases in the AMPS operational regional forecast model and the ERA5 model at two West Antarctic sites (McMurdo Station and the WAIS Divide). The better performance of ERA5 relative to AMPS is probably associated with the different model types, and not necessarily a function of the model parameterizations. In a forecast model, the simulations are free running after initialization, whereas in a reanalysis model, the simulations are constrained by frequent observation assimilation. Therefore, one should expect a less skillful performance by AMPS relative to ERA5. An evaluation of a climate model's performance over these two sites is also possible, given the spatial extent of high correlation of atmospheric parameters over McMurdo Station and the WAIS Divide with the regions surrounding the two sites (see Figs. S3-S5 in the supplemental material), and would be able to complement this study.

From the analysis presented above, we deduce the following:

- Both ERA5 and AMPS exhibit mean negative LW $\downarrow$ biases of more than $14 \mathrm{~W} \mathrm{~m}^{-2}$, with high SDs $\left(>26 \mathrm{~W} \mathrm{~m}^{-2}\right)$.

- The LW $\downarrow$ during clear-sky periods are mostly underestimated in both models and at both sites by a few watts per square meter (negative medians). However, ERA5 slightly overestimates (on average) the LW $\downarrow$ at the WAIS Divide. The low bias values near $0 \mathrm{~W} \mathrm{~m}^{-2}$ in ERA5 (at both sites) and AMPS (at McMurdo) are the results of the clear-sky underestimation instances due to the dryer atmosphere, balanced by overestimation periods induced by excess production of ice clouds when they are not observed.

- The LW $\downarrow$ during ice-cloud occurrence has a large variability ( $\mathrm{SD} \geq 21 \mathrm{~W} \mathrm{~m}^{-2}$ ), although the models manage to produce ice clouds on most of these times.
During these periods, AMPS has a negative LW $\downarrow$ bias with a mean magnitude larger than $21 \mathrm{~W} \mathrm{~m}^{-2}$, while ERA5 shows a mixed behavior with LW $\downarrow$ underestimation and overestimation (of several watts per square meter) at McMurdo and the WAIS, respectively.

- Liquid-bearing cloud-layer (LBCL) occurrences produce the largest (negative) LW $\downarrow$ bias in both models. The biases are accentuated during the occurrence of "opaque" LBCLs (LWP $\geq 25 \mathrm{~g} \mathrm{~m}^{-2}$ ), with mean magnitudes larger than 51 and $43 \mathrm{~W} \mathrm{~m}^{-2}$ in AMPS and ERA5, respectively. These large biases are mainly the result of deficient/lack of condensate production in the models.

- Both models produce too much ice and too little liquid at the West Antarctic sites. We hypothesize that excessive ice formation and growth in the models may ultimately result in the dry and liquid-deficient atmosphere.

- The model LW $\downarrow$ errors during clear-sky periods are strongly dependent on the annual cycle, while the errors during cloud occurrence are more dependent on the representation and prediction of cloud processes.

- AMPS potentially produces more and/or stronger surface temperature inversions, and both models tend to produce additional and/or more intense surface moisture inversions.

Diminution of the large model LW $\downarrow$ biases by treatment of their sources could increase the accuracy of the surface energy budget estimation, and potentially also improve the credibility of climate projections. Different choices of the initial and lateral boundary conditions applied in the models have been shown in previous studies to be capable of reducing these biases (e.g., Bromwich et al. 2011, 2013; Hines et al. 2019). Small changes in the AMPS LW $\downarrow$ bias at McMurdo Station as a function of the model runtime (not shown) suggest that the initial conditions could play a significant role in the disagreement of the model with the observations. The initial boundary conditions might also have a significant influence on the ERA5 biases because the model diagnoses convection (ECMWF 2016, chapter 6), which (rarely) may take place in the model representation of the Antarctic atmosphere. The impact of the initial and boundary conditions on the LW $\downarrow$ model output will be the topic of future studies.

The LW $\downarrow$ biases could also be influenced by the model microphysical scheme. Previous reports have demonstrated better model performance in predicting the surface radiation when more advanced microphysical parameterization schemes are used (e.g., Hines et al. 
2019; Listowski and Lachlan-Cope 2017). Recently, Barrett et al. (2017a,b) concluded, based on examination of large-scale models and midlatitude measurements, that the main cause for liquid deficiency in climate models is the results of the coarse resolution in the models combined with the parameterization of the ice-growth processes. Exploring this potential bias source [e.g., by implementing a higher vertical resolution or the parameterization introduced by Barrett et al. (2017b)] might improve the large-scale model representation of Antarctic mixed-phase clouds, and consequently, the LW $\downarrow$ biases as well.

Finally, cloud properties and processes are influenced by limited-aerosol regimes (e.g., Fridlind and Ackerman 2018; Mauritsen et al. 2011), such as those found in Antarctica (e.g., Shaw 1980, 1988). The impact of these Antarctic regimes and the sharp contrast in aerosolparticle concentrations relative to other regions (e.g., Holben et al. 2001; Spracklen et al. 2008) on the model representation of clouds warrant further investigation. Different methods for the determination of aerosol concentrations in large-scale models might reduce the LW $\downarrow$ and other model biases that are related to the aerosol indirect effect in the high-latitude regions (e.g., cloud reflectivity; McCoy et al. 2015; VergaraTemprado et al. 2018). However, the exact impact of the aerosol indirect effect and its representation in models are still highly active fields of research (e.g., Christensen et al. 2016; Fridlind and Ackerman 2018; Garrett and Zhao 2006; Jackson et al. 2012; Lubin and Vogelmann 2006, 2007; McFarquhar et al. 2011) and debate (in a global context; cf. Rosenfeld et al. 2019; Sato et al. 2018), which necessitates further study.

The quantification of the impact of each of these four plausible sources and the mitigation of the LW $\downarrow$ biases via treatment of these sources remain two major modelspecific problems. Because of the interplay between the sources, for example, the vertical resolution impact on the aerosol representation, which controls the cloud microphysical scheme, bulk analysis would likely overlook some of the feedbacks in the representation of clouds in different models. Therefore, we suggest that a case-study approach is more suitable for this type of research, as it allows for independent investigation of the different sources of error, for example, with the use of model sensitivity tests. Additional comprehensive Antarctic field campaigns such as AWARE could benefit this type of studies as well, by providing valuable datasets for model intercomparisons. Ongoing and future studies will focus on this problem in forecast, reanalysis, and climate model perspectives, and, hopefully, assist in addressing the representation of the LW surface energy budget in these models.
Acknowledgments. AWARE is supported by the DOE ARM Climate Research Facility and NSF Division of Polar Programs. The data used in this study are available in the ARM data archive (http://www.archive. arm.gov). The HSRL data can be obtained from the ARM archive or from the University of WisconsinMadison HSRL Lidar Group (http://lidar.ssec.wisc. edu). AMPS data can be requested from the Ohio State University Polar Meteorology Group (http:// polarmet.osu.edu/AMPS/). ERA5 data are accessible via the Copernicus Climate Change Service (C3S) Climate Data Store (CDS; https://cds.climate.copernicus. eu). The authors wish to thank Fuqing Zhang for the fruitful discussions. I.S. and J.V. are supported by the National Science Foundation Grant PLR-1443495 and by the DOE Grant DE-SC0017981. D.H.B. and S.H.W. are supported by National Science Foundation Grant PLR-1443443 and by DOE Grant DE-SC0017981. Contribution 1583 of Byrd Polar and Climate Research Center. A.F. is supported by the NASA Radiation Science and Modeling, Analysis and Prediction programs.

\section{REFERENCES}

Andreas, A., M. Dooraghi, A. Habte, M. Kutchenreiter, I. Reda, and M. Sengupta, 2018: Solar Infrared Radiation Station (SIRS), Sky Radiation (SKYRAD), Ground Radiation (GNDRAD), and Broadband Radiometer Station (BRS) Instrument Handbook. DOE Office of Science, Office of Biological and Environmental Research, DOE/SC-ARM-TR-025, 58 pp., https://doi.org/10.2172/1432706.

Barrett, A. I., R. J. Hogan, and R. M. Forbes, 2017a: Why are mixedphase altocumulus clouds poorly predicted by large-scale models? Part 1. Physical processes. J. Geophys. Res. Atmos., 122, 9903-9926, https://doi.org/10.1002/2016JD026321.

,-- , and,$- 2017 \mathrm{~b}$ : Why are mixed-phase altocumulus clouds poorly predicted by large-scale models? Part 2 . Vertical resolution sensitivity and parameterization. J. Geophys. Res. Atmos., 122, 9927-9944, https://doi.org/10.1002/2016JD026322.

Belosi, F., G. Santachiara, and F. Prodi, 2014: Ice-forming nuclei in Antarctica: New and past measurements. Atmos. Res., 145-146, 105-111, https://doi.org/10.1016/J.ATMOSRES.2014.03.030.

Bennartz, R., and Coauthors, 2013: July 2012 Greenland melt extent enhanced by low-level liquid clouds. Nature, 496, 83-86, https://doi.org/10.1038/nature12002.

Bromwich, D. H., J. P. Nicolas, and A. J. Monaghan, 2011: An assessment of precipitation changes over Antarctica and the Southern Ocean since 1989 in contemporary global reanalyses. J. Climate, 24, 4189-4209, https://doi.org/10.1175/2011JCLI4074.1. - F. O. Otieno, K. M. Hines, K. W. Manning, and E. Shilo, 2013: Comprehensive evaluation of Polar Weather Research and Forecasting Model performance in the Antarctic. J. Geophys. Res., 118, 274-292, https://doi.org/10.1029/2012JD018139.

Cadeddu, M. P., 2010: G-Band Vapor Radiometer Profiler (GVRP) Handbook. DOE Office of Science, Office of Biological and Environmental Research, DOE/SC-ARM/TR-091, $14 \mathrm{pp}$. 
—, V. H. Payne, S. A. Clough, K. Cady-Pereira, and J. C. Liljegren, 2007: Effect of the oxygen line-parameter modeling on temperature and humidity retrievals from ground-based microwave radiometers. IEEE Trans. Geosci. Remote Sens., 45, 2216-2223, https://doi.org/10.1109/TGRS.2007.894063.

— , D. D. Turner, and J. C. Liljegren, 2009: A neural network for real-time retrievals of PWV and LWP from Arctic millimeterwave ground-based observations. IEEE Trans. Geosci. Remote Sens., 47, 1887-1900, https://doi.org/10.1109/TGRS.2009. 2013205.

Carrasco, J. F., and D. H. Bromwich, 1993: Mesoscale cyclogenesis dynamics over the southwestern Ross Sea, Antarctica. J. Geophys. Res., 98, 12973-12 995, https://doi.org/10.1029/ 92JD02821.

,-- , and A. J. Monaghan, 2003: Distribution and characteristics of mesoscale cyclones in the Antarctic: Ross Sea eastward to the Weddell Sea. Mon. Wea. Rev., 131, 289-301, https://doi.org/ 10.1175/1520-0493(2003)131<0289:DACOMC >2.0.CO;2.

Cesana, G., J. E. Kay, H. Chepfer, J. M. English, and G. de Boer, 2012: Ubiquitous low-level liquid-containing Arctic clouds: New observations and climate model constraints from CALIPSO-GOCCP. Geophys. Res. Lett., 39, L20804, https:// doi.org/10.1029/2012GL053385.

Christensen, M. W., Y.-C. Chen, and G. L. Stephens, 2016: Aerosol indirect effect dictated by liquid clouds. J. Geophys. Res. Atmos., 121, 14 636-14 650, https://doi.org/10.1002/2016JD025245.

Coggins, J. H. J., and A. J. McDonald, 2015: The influence of the Amundsen Sea Low on the winds in the Ross Sea and surroundings: Insights from a synoptic climatology. J. Geophys. Res., 120, 2167-2189, https://doi.org/10.1002/2014JD022830.

de Boer, G., H. Morrison, M. D. Shupe, and R. Hildner, 2011: Evidence of liquid dependent ice nucleation in high-latitude stratiform clouds from surface remote sensors. Geophys. Res. Lett., 38, L01803, https://doi.org/10.1029/2010GL046016.

Dee, D. P., and Coauthors, 2011: The ERA-Interim reanalysis: Configuration and performance of the data assimilation system. Quart. J. Roy. Meteor. Soc., 137, 553-597, https://doi.org/ 10.1002/qj.828.

ECMWF, 2016: Part IV: Physical processes. ECMWF IFS Doc. CY41R2, 213 pp., https://www.ecmwf.int/node/16648.

Eloranta, E. W., 2005: High spectral resolution lidar. Lidar: RangeResolved Optical Remote Sensing of the Atmosphere, Springer, 143-163.

Flynn, C. J., A. Mendozaa, Y. Zhengb, and S. Mathurb, 2007: Novel polarization-sensitive micropulse lidar measurement technique. Opt. Express, 15, 2785-2790, https://doi.org/10.1364/ OE.15.002785.

Francis, J. A., and E. Hunter, 2006: New insight into the disappearing Arctic sea ice. Eos, Trans. Amer. Geophys. Union, 87, 509-511, https://doi.org/10.1029/2006EO460001.

Fréville, H., and Coauthors, 2014: Using MODIS land surface temperatures and the Crocus snow model to understand the warm bias of ERA-Interim reanalyses at the surface in Antarctica. Cryosphere, 8, 1361-1373, https://doi.org/10.5194/tc-81361-2014.

Fridlind, A. M., and A. S. Ackerman, 2018: Simulations of Arctic mixed-phase boundary layer clouds: Advances in understanding and outstanding questions. Mixed-Phase Clouds Observations and Modeling, C. Andronache, Ed., Elsevier, 153-183, https://doi.org/10.1016/B978-0-12-810549-8.00007-6.

Garrett, T. J., and C. Zhao, 2006: Increased Arctic cloud longwave emissivity associated with pollution from mid-latitudes. $\mathrm{Na}$ ture, 440, 787, https://doi.org/10.1038/nature04636.
Harrington, J. Y., K. Sulia, and H. Morrison, 2013: A method for adaptive habit prediction in bulk microphysical models. Part I: Theoretical development. J. Atmos. Sci., 70, 349-364, https:// doi.org/10.1175/JAS-D-12-040.1.

Hersbach, H., and D. Dee, 2016: ERA5 reanalysis is in production. ECMWF Newsletter, No. 147, ECMWF, Reading, United Kingdom, https://www.ecmwf.int/en/newsletter/147/news/era5reanalysis-production.

Hines, K. M., and D. H. Bromwich, 2008: Development and testing of Polar Weather Research and Forecasting (WRF) Model. Part I: Greenland ice sheet meteorology. Mon. Wea. Rev., 136, 1971-1989, https://doi.org/10.1175/2007MWR2112.1.

_ - - S.-H. Wang, I. Silber, J. Verlinde, and D. Lubin, 2019: Microphysics of summer clouds in central West Antarctica simulated by Polar WRF and AMPS. Atmos. Chem. Phys., https://doi.org/10.5194/acp-2018-1251, in press.

Hogan, R. J., M. P. Mittermaier, and A. J. Illingworth, 2006: The retrieval of ice water content from radar reflectivity factor and temperature and its use in evaluating a mesoscale model. J. Appl. Meteor. Climatol., 45, 301-317, https://doi.org/ 10.1175/JAM2340.1.

Holben, B. N., and Coauthors, 2001: An emerging ground-based aerosol climatology: Aerosol optical depth from AERONET. J. Geophys. Res., 106, 12 067-12 097, https://doi.org/10.1029/ 2001JD900014.

Holdridge, D., M. Ritsche, J. Prell, and R. Coulter, 2011: BalloonBorne Sounding System (SONDE) Handbook. DOE Office of Science, Office of Biological and Environmental Research ARM-TR-029, 33 pp., https://www.arm.gov/publications/ tech_reports/handbooks/sonde_handbook.pdf.

Hong, S.-Y., J. Dudhia, and S.-H. Chen, 2004: A revised approach to ice microphysical processes for the bulk parameterization of clouds and precipitation. Mon. Wea. Rev., 132, 103-120, https:// doi.org/10.1175/1520-0493(2004)132<0103:ARATIM>2.0.CO;2.

Jackson, R. C., and Coauthors, 2012: The dependence of ice microphysics on aerosol concentration in Arctic mixed-phase stratus clouds during ISDAC and M-PACE. J. Geophys. Res., 117, D15207, https://doi.org/10.1029/2012JD017668.

King, J. C., and Coauthors, 2015: Validation of the summertime surface energy budget of Larsen C Ice Shelf (Antarctica) as represented in three high-resolution atmospheric models. J. Geophys. Res. Atmos., 120, 1335-1347, https://doi.org/ 10.1002/2014JD022604.

Klein, S. A., and Coauthors, 2009: Intercomparison of model simulations of mixed-phase clouds observed during the ARM Mixed-Phase Arctic Cloud Experiment. I: Single-layer cloud. Quart. J. Roy. Meteor. Soc., 135, 979-1002, https://doi.org/ 10.1002/qj.416.

Lenaerts, J. T. M., K. Van Tricht, S. Lhermitte, and T. S. L'Ecuyer, 2017: Polar clouds and radiation in satellite observations, reanalyses, and climate models. Geophys. Res. Lett., 44, 33553364, https://doi.org/10.1002/2016GL072242.

Listowski, C., and T. Lachlan-Cope, 2017: The microphysics of clouds over the Antarctic Peninsula-Part 2: Modelling aspects within Polar WRF. Atmos. Chem. Phys., 17, 10195 10 221, https://doi.org/10.5194/acp-17-10195-2017.

Lubin, D., and A. M. Vogelmann, 2006: A climatologically significant aerosol longwave indirect effect in the Arctic. Nature, 439, 453, https://doi.org/10.1038/nature04449.

, and - 2007: Expected magnitude of the aerosol shortwave indirect effect in springtime Arctic liquid water clouds. Geophys. Res. Lett., 34, L11801, https://doi.org/10.1029/ 2006GL028750. 
, D. H. Bromwich, L. M. Russell, J. Verlinde, and A. M. Vogelmann, 2015: ARM West Antarctic Radiation Experiment (AWARE) Science Plan. DOE Office of Science, Office of Biological and Environmental Research, DOE/SC-ARM15-040, 20 pp., https://www.arm.gov/publications/programdocs/ doe-sc-arm-15-040.pdf.

Mauritsen, T., and Coauthors, 2011: An Arctic CCN-limited cloudaerosol regime. Atmos. Chem. Phys., 11, 165-173, https:// doi.org/10.5194/acp-11-165-2011.

McCoy, D. T., S. M. Burrows, R. Wood, D. P. Grosvenor, S. M. Elliott, P.-L. Ma, P. J. Rasch, and D. L. Hartmann, 2015: Natural aerosols explain seasonal and spatial patterns of Southern Ocean cloud albedo. Sci. Adv., 1, e1500157, https:// doi.org/10.1126/sciadv.1500157.

McFarquhar, G. M., and Coauthors, 2011: Indirect and SemiDirect Aerosol Campaign. Bull. Amer. Meteor. Soc., 92, 183-201, https://doi.org/10.1175/2010BAMS2935.1.

Miller, N. B., M. D. Shupe, C. J. Cox, V. P. Walden, D. D. Turner, and K. Steffen, 2015: Cloud radiative forcing at Summit, Greenland. J. Climate, 28, 6267-6280, https://doi.org/10.1175/ JCLI-D-15-0076.1.

Monaghan, A. J., D. H. Bromwich, J. G. Powers, and K. W. Manning, 2005: The climate of the McMurdo, Antarctica, region as represented by one year of forecasts from the Antarctic Mesoscale Prediction System. J. Climate, 18, 1174-1189, https://doi.org/10.1175/JCLI3336.1.

Morris, V. R., 2006: Microwave radiometer handbook. DOE Office of Science, Office of Biological and Environmental Research, ARM-TR-016, 23 pp., https://www.arm.gov/publications/tech_ reports/handbooks/mwr_handbook.pdf.

_ 2016: Ceilometer Instrument Handbook. DOE Office of Science, Office of Biological and Environmental Research, DOE/SC-ARM-TR-020, 26 pp., https:/www.arm.gov/publications/ tech_reports/handbooks/ceil_handbook.pdf.

Murphy, D. M., and T. Koop, 2005: Review of the vapour pressures of ice and supercooled water for atmospheric applications. Quart. J. Roy. Meteor. Soc., 131, 1539-1565, https://doi.org/ 10.1256/qj.04.94.

Nicolas, J. P., and D. H. Bromwich, 2011: Climate of West Antarctica and influence of marine air intrusions. J. Climate, 24, 49-67, https://doi.org/10.1175/2010JCLI3522.1.

— , and Coauthors, 2017: January 2016 extensive summer melt in West Antarctica favoured by strong El Niño. Nat. Commun., 8, 15799, https://doi.org/10.1038/ncomms15799.

Nigro, M. A., and J. J. Cassano, 2014: Analysis of the Ross Ice Shelf airstream forcing mechanisms using self-organizing maps. Mon. Wea. Rev., 142, 4719-4734, https://doi.org/10.1175/ MWR-D-14-00077.1.

Ohmura, A., 2001: Physical basis for the temperature-based meltindex method. J. Appl. Meteor., 40, 753-761, https://doi.org/ 10.1175/1520-0450(2001)040<0753:PBFTTB $>2.0$. CO 2

Persson, P. O. G., M. D. Shupe, D. Perovich, and A. Solomon, 2017: Linking atmospheric synoptic transport, cloud phase, surface energy fluxes, and sea-ice growth: Observations of midwinter SHEBA conditions. Climate Dyn., 49, 1341-1364, https:// doi.org/10.1007/s00382-016-3383-1.

Pithan, F., and Coauthors, 2018: Role of air-mass transformations in exchange between the Arctic and mid-latitudes. Nat. Geosci., 11, 805-812, https://doi.org/10.1038/s41561-018-0234-1.

Powers, J. G., K. W. Manning, D. H. Bromwich, J. J. Cassano, and A. M. Cayette, 2012: A decade of Antarctic science support through AMPS. Bull. Amer. Meteor. Soc., 93, 1699-1712, https://doi.org/10.1175/BAMS-D-11-00186.1.
Rosenfeld, D., Y. Zhu, M. Wang, Y. Zheng, T. Goren, and S. Yu, 2019: Aerosol-driven droplet concentrations dominate coverage and water of oceanic low-level clouds. Science, $\mathbf{3 6 3}$, eaav0566, https://doi.org/10.1126/science.aav0566.

Sato, Y., D. Goto, T. Michibata, K. Suzuki, T. Takemura, H. Tomita, and T. Nakajima, 2018: Aerosol effects on cloud water amounts were successfully simulated by a global cloudsystem resolving model. Nat. Commun., 9, 985, https://doi.org/ 10.1038/s41467-018-03379-6.

Scott, R. C., and D. Lubin, 2014: Mixed-phase cloud radiative properties over Ross Island, Antarctica: The influence of various synoptic-scale atmospheric circulation regimes. J. Geophys. Res., 119, 6702-6723, https://doi.org/10.1002/ 2013JD021132.

, and - 2016: Unique manifestations of mixed-phase cloud microphysics over Ross Island and the Ross Ice Shelf, Antarctica. Geophys. Res. Lett., 43, 2936-2945, https://doi.org/ 10.1002/2015GL067246.

_ J. P. Nicolas, D. H. Bromwich, J. R. Norris, and D. Lubin, 2019: Meteorological drivers and large-scale climate forcing of West Antarctic surface melt. J. Climate, 32, 665-684, https:// doi.org/10.1175/JCLI-D-18-0233.1.

Sedlar, J., and M. Tjernström, 2017: Clouds, warm air, and a climate cooling signal over the summer Arctic. Geophys. Res. Lett., 44, 1095-1103, https://doi.org/10.1002/2016GL071959.

Shaw, G. E., 1980: Optical, chemical and physical properties of aerosols over the Antarctic ice sheet. Atmos. Environ., 14, 911-921, https://doi.org/10.1016/0004-6981(80)90004-9.

_ 1988: Antarctic aerosols: A review. Rev. Geophys., 26, 89112, https://doi.org/10.1029/RG026i001p00089.

Shupe, M. D., and J. M. Intrieri, 2004: Cloud radiative forcing of the Arctic surface: The influence of cloud properties, surface albedo, and solar zenith angle. J. Climate, 17, 616-628, https://doi.org/10.1175/1520-0442(2004)017<0616:CRFOTA > 2.0.CO;2.

Silber, I., J. Verlinde, E. W. Eloranta, and M. Cadeddu, 2018a: Antarctic cloud macrophysical, thermodynamic phase, and atmospheric inversion coupling properties at McMurdo Station. Part I: Principal data processing and climatology. J. Geophys. Res. Atmos., 123, 6099-6121, https://doi.org/ 10.1029/2018JD028279.

,,--- C. J. Flynn, and D. M. Flynn, 2018b: Reprocessed MPL data sets. ARM Data Center, accessed 4 October 2018, https://doi.org/10.5439/1468777.

- - M. Cadeddu, C. J. Flynn, A. M. Vogelmann, and E. W. Eloranta, 2019: Antarctic cloud macrophysical, thermodynamic phase, and atmospheric inversion coupling properties at McMurdo Station. Part II: Radiative impact during different synoptic regimes. J. Geophys. Res. Atmos., 124, 1697-1719, https://doi.org/10.1029/2018JD029471.

Spracklen, D. V., and Coauthors, 2008: Contribution of particle formation to global cloud condensation nuclei concentrations. Geophys. Res. Lett., 35, L06808, https://doi.org/10.1029/ 2007GL033038.

Tiedtke, M., 1993: Representation of clouds in large-scale models. Mon. Wea. Rev., 121, 3040-3061, https://doi.org/10.1175/15200493(1993) $121<3040$ :ROCILS $>2.0$.CO;2.

Turner, D. D., S. A. Clough, J. C. Liljegren, E. E. Clothiaux, K. E. Cady-Pereira, and K. L. Gaustad, 2007a: Retrieving liquid water path and precipitable water vapor from the Atmospheric Radiation Measurement (ARM) Microwave Radiometers. IEEE Trans. Geosci. Remote Sens., 45, 3680-3690, https://doi.org/10.1109/TGRS.2007.903703. 
and Coauthors, 2007b: Thin liquid water clouds: Their importance and our challenge. Bull. Amer. Meteor. Soc., 88, 177 190, https://doi.org/10.1175/BAMS-88-2-177.

Välisuo, I., T. Vihma, and J. C. King, 2014: Surface energy budget on Larsen and Wilkins ice shelves in the Antarctic Peninsula: Results based on reanalyses in 1989-2010. Cryosphere, 8, 1519-1538, https://doi.org/10.5194/tc-8-1519-2014.

Valkonen, T., T. Vihma, M. M. Johansson, and J. Launiainen, 2014: Atmosphere-sea ice interaction in early summer in the Antarctic: Evaluation and challenges of a regional atmospheric model. Quart. J. Roy. Meteor. Soc., 140, 1536-1551, https:// doi.org/10.1002/qj.2237.

van Diedenhoven, B., A. M. Fridlind, A. S. Ackerman, E. W. Eloranta, and G. M. McFarquhar, 2009: An evaluation of ice formation in large-eddy simulations of supercooled Arctic stratocumulus using ground-based lidar and cloud radar. J. Geophys. Res., 114, D10203, https://doi.org/10.1029/2008JD011198.

Van Tricht, K., and Coauthors, 2016: Clouds enhance Greenland ice sheet meltwater runoff. Nat. Commun., 7, 10266, https:// doi.org/10.1038/ncomms10266.

van Wessem, J. M., and Coauthors, 2018: Modelling the climate and surface mass balance of polar ice sheets using RACMO2-Part 2: Antarctica (1979-2016). Cryosphere, 12, 1479-1498, https://doi.org/10.5194/tc-12-1479-2018.

Vergara-Temprado, J., and Coauthors, 2018: Strong control of Southern Ocean cloud reflectivity by ice-nucleating particles.
Proc. Natl. Acad. Sci. USA, 115, 2687-2692, https://doi.org/ 10.1073/pnas.1721627115.

Wang, K., and R. E. Dickinson, 2013: Global atmospheric downward longwave radiation at the surface from ground-based observations, satellite retrievals, and reanalyses. Rev. Geophys., 51, 150-185, https://doi.org/10.1002/rog.20009.

Widener, K., N. Bharadwaj, and K. Johnson, 2012: Ka-Band ARM Zenith Radar (KAZR) Instrument Handbook. PNNL, 25 pp., https://www.arm.gov/publications/tech_reports/handbooks/ kazr_handbook.pdf.

Wille, J. D., D. H. Bromwich, M. A. Nigro, J. J. Cassano, M. Mateling, M. A. Lazzara, and S.-H. Wang, 2016: Evaluation of the AMPS boundary layer simulations on the Ross Ice Shelf with tower observations. J. Appl. Meteor. Climatol., 55, 2349-2367, https://doi.org/10.1175/JAMC-D-16-0032.1.

, - J. J. Cassano, M. A. Nigro, M. E. Mateling, and M. A. Lazzara, 2017: Evaluation of the AMPS boundary layer simulations on the Ross Ice Shelf, Antarctica, with unmanned aircraft observations. J. Appl. Meteor. Climatol., 56, 22392258, https://doi.org/10.1175/JAMC-D-16-0339.1.

Witze, A., 2016: Antarctic clouds studied for first time in five decades. Nature, 529, 12, https://doi.org/10.1038/529012a.

Woods, C., R. Caballero, and G. Svensson, 2013: Large-scale circulation associated with moisture intrusions into the Arctic during winter. Geophys. Res. Lett., 40, 4717-4721, https:// doi.org/10.1002/grl.50912. 